Revista Iberoamericana, Vol. LXXIV, Núm. 222, Enero-Marzo 2008, 1-

\title{
CONTRADISCURSO Y PARATEXTUALIDAD EN ELEGÍA SIN NOMBRE DE EMILIO BALLAGAS
}

\author{
POR \\ WILFREDO HERNÁNDEZ \\ Allegheny College
}

Aunque en la literatura hispanoamericana publicada aproximadamente entre 1880 y 1950 la homosexualidad masculina fue relativamente poco tratada, los escritores que la representaron desarrollaron al menos dos corrientes ideológicas claramente articuladas. ${ }^{1}$ La principal, que apareció después de que los médicos hubieran codificado el homoerotismo como una patología, asumió esta conceptualización como válida y fue usada por escritores públicamente identificados como heterosexuales. Entre éstos están figuras actualmente muy conocidas como José Martí (“Oscar Wilde”) y Rubén Darío ("Purificaciones de la piedad”) y casi olvidadas como José González Castillo (Los invertidos) y Alfonso Hernández Catá (El ángel de Sodoma). ${ }^{2}$ La otra tradición alcanzó fuerza en las primeras décadas del siglo xx y, en alianza con el contradiscurso homosexual que por entonces circulaba, se opuso a los presupuestos de la corriente hegemónica. Significativamente, todos sus practicantes fueron poetas públicamente identificados como homosexuales; entre los más conocidos están Porfirio Barba Jacob (Flores negras), Xavier Villaurrutia (Nostalgia de la muerte), Salvador Novo (Nuevo amor), Emilio Ballagas (Elegía sin nombre) y Juan Rodolfo Wilcock (Paseo sentimental). ${ }^{3}$

\footnotetext{
${ }^{1}$ Agradezco a los lectores anónimos de esta publicación, algunos de cuyos comentarios y sugerencias fueron decisivos en ayudarme a precisar mejor varias de las ideas aquí articuladas. También deseo expresar mi más sincera gratitud a Alicia Covarrubias y Barbara Riess por las meticulosas lecturas y revisiones que gentilmente hicieron de este ensayo.

${ }^{2}$ Agrupo a estos escritores tomando en cuenta las conclusiones de estudios publicados en los últimos lustros. Sobre Darío y Martí, el artículo de Molloy (1992) fue el pionero en llamar la atención a la homofobia articulada en varios ensayos entre 1880 y 1900; sobre González Castillo, el libro de Salessi provee uno de los primeros análisis de Los invertidos; y sobre Hernández Catá, el libro de Bejel contiene un valioso comentario.

${ }^{3}$ Para casi todos los escritores de esta corriente se han publicado importantes trabajos enfocados en las representaciones alternas de homoerotismo. Sobre Barba Jacob hay tres que merecen atención: el prólogo que Luis Antonio de Villena escribió para la antología que editó en España; la biografía publicada por Fernando Vallejo; y la tesis doctoral que Carmen Valle le dedicó a su poesía. Sobre el grupo "Contemporáneos" en general, los textos de obligatoria consulta son los de Sheridan, Balderston y Oropesa; sobre Villaurrutia, los estudios de Quiroga e Irwin; y sobre Novo, la introducción de Monsiváis a la primera edición de La estatua de sal y el libro de Acero. Sobre Ballagas son útiles los estudios de Piñera, Barredas y Rodríguez Núñez. Para el interesado en contrastar el tipo de lecturas que prestan atención a temas de género con otros que los obviaron, es interesante el libro de Rice.
} 
En este ensayo, dividido en tres partes, relaciono la obra de Emilio Ballagas (Cuba, 1908-1956) con el discurso homosexual alternativo que circuló entre 1920 y 1940. En la primera sección plantearé que, influido por la lectura de Corydon de André Gide y la impronta de otros escritores homosexuales coetáneos, este escritor comenzó a incluir desde mediados de los años treinta representaciones homoeróticas en su poesía, alternativas a las que circulaban en la época. En la segunda parte analizaré los elementos liminares que se encuentran en Elegía sin nombre (1936), el texto con que Ballagas inauguró la representación del tema en la lírica cubana del siglo xx. Recurriendo a la teoría de la paratextualidad desarrollada por Gerard Genette y analizando el contexto represivo en que Ballagas escribió el poema, mostraré que tanto su título como los dos epígrafes que lo preceden conforman una especie de clave para leerlo como un texto contradiscursivo. El estudio de estos elementos -centro literal y figurado de este trabajo- lo complementaré en la última parte con una glosa del poema, la cual revelará tanto su contenido codificado como los recursos retóricos que Ballagas usó para representar el homoerotismo de forma novedosa.

\section{El CONTRADISCURSO HOMOSEXUAL EN EL PRIMER TERCIO DEL SIGLO XX}

Con la publicación de la versión completa de Corydon (en francés en 1924; la traducción española apareció en 1928), André Gide (1869-1951) ejerció una influencia decisiva en la divulgación de planteamientos dirigidos a probar que la propuesta creada por los científicos decimonónicos sobre el homoerotismo estaba prejuiciada y era, en consecuencia, de dudosa validez. Escrito a manera de un diálogo platónico, el libro presenta a un médico homosexual que en cuatro sesiones defiende la normalidad de su erotismo apoyándose en fuentes científicas, históricas y artísticas. La obra, producida en un clima en que las relaciones sexuales entre hombres eran ilegales en casi todos los países occidentales, fue decisiva en divulgar en el ámbito internacional un compendio de argumentos con que disentir de la homofobia institucionalizada desde aproximadamente 1870. Como resultado de la controversia que se produjo a raíz de la edición y traducciones de la obra, su autor, quien ya era ampliamente conocido gracias a la publicación de novelas como El inmoralista y La sinfonía pastoral, se volvió una figura muy influyente en el debate internacional de política homosexual. La publicación en 1924 de la edición definitiva de su autobiografía Si le grain ne meurt [Si la semilla no se seca], en la que reveló su sexualidad, y que constituyó posiblemente la primera vez que un escritor contemporáneo famoso reconocía que era homosexual, también contribuyó a que se lo conociera aún más como opositor a la corriente hegemónica. Por estas razones, sus libros, además del impacto de sus ideas, proveyeron incluso modelos retóricos para la exposición del tema. ${ }^{4}$

Aunque el estudio del influjo que Gide tuvo en la audiencia homosexual hispana aún está por emprenderse, su efecto puede apreciarse en dos escritores nacidos a principios del

\footnotetext{
${ }^{4}$ Pollard analiza Corydon tomando en cuenta las ideas intelectuales de la época. Es un libro de consulta obligatoria para entender las múltiples referencias cultas, así como el contexto en que surgieron los planteamientos que Gide articuló en ese libro central del contradiscurso homosexual. En inglés existe la traducción de Si le grain ne meurt que Dorothy Bussy hizo en 1935. Hay traducciones recientes de ambas obras en español, indicio del interés que aún despiertan.
} 
siglo pasado hoy ampliamente conocidos: el español Luis Cernuda (1902-1963) y el mexicano Xavier Villaurrutia (1903-1950). ${ }^{5}$ En Cernuda, las enseñanzas de Gide implicaron la superación de los prejuicios con los que había crecido, lo que le ayudó a alcanzar gradualmente la seguridad para escribir sobre su sexualidad desde mediados de los años treinta. Como él mismo afirmó: "esa lectura me abría el camino para resolver, o para reconciliarme, con un problema vital mío decisivo" (1975: 901). Octavio Paz, uno de los primeros comentaristas en notar la influencia del galo en Cernuda, afirmó que: "Gracias al moralista francés, se acepta a sí mismo; desde entonces su homosexualismo no será ni enfermedad ni pecado sino destino libremente aceptado y vivido" (175). Por su parte, en 1932, Villaurrutia resumía su credo, profundamente marcado por las propuestas del europeo:

Es la moral de Gide la que nos interesa, lo que me interesa. Humana, profunda, valiente, ayuda a vivir. Hazte quien eres, decía Nietzsche. Vive como eres, parece decir André Gide. Usted sabe que por lo que se refiere a esa familiaridad con la obra moral de Gide, nosotros no hicimos sino coincidir con los nuevos espíritus del mundo que, del mismo modo que nosotros, encontraron en su obra una incitación a la falta de hipocrecía moral. (citado en Monsiváis 26)

El mexicano subraya la novedad y el atractivo de la actitud defendida por el francés, quien al rechazar los prejuicios generales que obligaban a que los homosexuales se percibieran como enfermos, propugnaba, por el contrario, la aceptación de su sexualidad como una forma erótica sana y alternativa. Reveladoramente, Villaurrutia aclara el tipo de discurso articulado por Gide ("la obra moral”) que había sido instrumental en el desarrollo de su actitud. La cita ("nosotros no hicimos”) también ilumina la profunda y decisiva impronta que el escritor francés tuvo, no sólo en él sino en todo un grupo de artistas emergentes a principios de la pasada centuria, algunos de los cuales formaron parte del grupo "Contemporáneos" (Salvador Novo) o estuvieron relacionados con ellos como por ejemplo el pintor Agustín Lazo.

Planteo que Emilio Ballagas, que había nacido en Camagüey, Cuba, en 1908 e iniciado su carrera literaria en 1931, fue otro de “los nuevos espríritus” en quienes las ideas éticas y literarias del autor de Corydon y sus seguidores tuvieron impacto. Al igual que en Cernuda -posiblemente el poeta hispano homosexual que más influyó en Ballagas- esto se observa en el tipo de escritura que comenzó a producir desde mediados de los treinta y en que el homoerotismo pasó a ocupar una posición privilegiada; siempre de manera codificada, pero distinta de las imágenes que circulaban comúnmente en Cuba. Así en 1936 publicó en folleto la Elegía sin nombre en cuya escritura había transfigurado, según un testigo coetáneo, una fallida relación sentimental con otro hombre (Piñera 198). Además, es posible que la impresión del opúsculo haya sido pagada por el mismo autor,

\footnotetext{
${ }^{5}$ A Alberto Mira se debe la primera aproximación al tema en el mundo hispánico. En una valiosa sección de su De Sodoma a Chueca analiza el impacto que Gide tuvo en España, en donde incluso se publicaron varios libros, como Contra Gide, de Emilio Donato, en que éste refutó los argumentos propuestos por el francés. Mira incluso basa uno de sus modelos de la representación de la homosexualidad en la cultura española precisamente en las ideas homófilas de Gide.
} 
siguiendo así a Gide, que había impreso privadamente las primeras ediciones de Corydon (Hanna 206). Desde 1936, Ballagas trató su sexualidad incluyéndola hasta en sus últimos libros, como ha mostrado recientemente Víctor Rodríguez Núñez (134-50).

El testimonio de Virgilio Piñera, que conoció a Ballagas y fue su amigo por muchos años, revela que numerosos contemporáneos del poeta captaron que su nueva escritura estaba influida por la corriente ideológica tipificada por Gide:

Cuando apareció la “Elegía” ciertos homosexuales de capilla y también ciertos intelectuales de capilla, creyeron tener a Dios cogido por las barbas. Aquéllos porque creyeron contar con un "canto de guerra”; éstos, con una pieza de convicción. Los primeros decían: "Por fin alguien nos representa”; los segundos: “Es poesía engagé, ya el uranismo cubano tiene su profeta”. (198)

Las dos facciones identificadas por el testigo, no excluyentes la una de la otra, percibieron la publicación como la primera ocasión en que un escritor cubano se oponía públicamente al discurso de sexualidad impuesto desde fines del siglo xix e ilustrado por médicos de entonces (Benjamín de Céspedes y Luis Montané y Dardé) y escritores locales contemporáneos (Alfonso Hernández Catá). ${ }^{6}$ Esto se observa en el vocabulario que usaron para describir el poema: el primer grupo lo definió como un "canto de guerra” y una "pieza de convicción”; el segundo, como un texto "engagé” y adscrito al "uranismo”. Ambas caracterizaciones coinciden en apuntar a una praxis insubordinada del discurso sexual mayoritario; de hecho, el último grupo empleó la palabra "engagé” (comprometido en francés) en clara referencia a su defensor más conocido internacionalmente-André Gidey a los activistas que habían aceptado su liderazgo. Además, el otro vocablo (uranista), tiene también una proveniencia disidente, ya que se refiere a la teoría del tercer sexo propuesta por Karl Heinrich Ulrichs, uno de los creadores decimonónicos del contradiscurso homosexual (Lauritsen 9).

Lo que la reacción coetánea descrita por Piñera también revela es que si bien el contradiscurso era conocido en Cuba, en la literatura local aún no había surgido ningún escritor seguidor de las nuevas ideas. De hecho, si se compara la Elegía sin nombre con otros textos pertinentes escritos entre 1920 y 1940, se podrá llegar a la conclusión de que contenían tratamientos producidos en marcos ideológicos diametralmente opuestos. Posiblemente el mejor ejemplo de esta última producción sea la noveleta El ángel de Sodoma de Alfonso Hernández Catá, aparecida en 1928 y que según Gregorio Marañón, el más famoso sexólogo español de la época, "es la primera obra literaria importante que en nuestra lengua se ha construido sobre el argumento de una aberración de la sexualidad” (citado en Hernández Catá 13). ${ }^{7}$

\footnotetext{
${ }^{6}$ Además de Hernández Catá, hubo otros escritores cubanos que representaron la homosexualidad en este periodo. Los dos más importantes fueron Carlos Montenegro, quien publicó la novela Hombres sin mujer serializada en una revista en 1937 (Bejel 78) y al año siguiente en libro; y Ofelia Rodríguez Acosta, autora de dos novelas en que aparecen personajes secundarios, femeninos y masculinos, también homosexuales.

${ }^{7}$ Para hacerse una buena idea sobre el tratamiento de la homosexualidad en Cuba en el siglo XIX y las primeras décadas del xx, Bejel y Fowler proveen análisis altamente recomendables. Los estudios
} 
Desde el mismo comienzo del libro, la noción de decadencia tal como la entendían los escritores naturalistas permea el relato, que aparece bajo el eje de la caída material y espiritual de una familia cuya fortuna está a punto de derrumbarse. El narrador describe a los progenitores de forma invertida: aunque el padre es ciclópeo, tiene la cabeza chica; mientras la madre es menuda, es hacendosa. Poco después que ésta muere, el viudo, que está alcoholizado, sufre un accidente automovilístico y también perece. No es de extrañar que el hijo mayor de la pareja sea un personaje homosexual cuyo mismo nombre, José María, comprende simbólicamente los principios masculino y femenino. Cuando éste cumple la mayoría de edad conceptualiza su sexualidad: “¿De cuál antepasado le venía la degeneración? ¿O habría brotado en él por mal milagro, invistiéndole del funesto deshonor propio de la cabeza de una estirpe marcada por la naturaleza con la ambigüedad del hermafrodita?” (38). Poco después, el personaje empieza un proceso de represión de su erotismo y de intento de apegarse a la heterosexualidad normativa. Al cabo de varios años viaja a París donde al fin decide poner fin a su ascetismo pero, antes de que esto ocurriera, se suicida porque "la muerte lo evitaba todo, lo borraba todo..." (85).

En El ángel de Sodoma, Hernández Catá presenta a un sujeto que no puede aceptar su sexualidad porque había interiorizado lo que la ciencia proponía respecto a ella, es decir, que era una patología (“¿De cuál antepasado le venía la degeneración?”). Consciente de la profunda estigmatización que existía del homoerotismo en su sociedad ("funesto deshonor"), el personaje lucha contra su cuerpo e intenta apegarse a las normas generales. Sin embargo, como su sexualidad es innata no puede cambiarla. El suicidio del protagonista es, precisamente, resultado de su toma de conciencia de que la expresión de su erotismo estaba condenada al secreto o al desprecio, en caso de que lo revelara y expresara en público. A pesar de las anacrónicas alusiones religiosas presentes en el título de la novelita, el hecho de que el sexólogo peninsular más influyente de la época haya redactado un prólogo para acompañar su segunda edición, evidencia la comunidad ideológica existente entre un representante del discurso médico sobre sexualidad (el científico) y uno de sus divulgadores artísticos (el novelista). ${ }^{8}$

En cambio, en la Elegía sin nombre, como tendremos oportunidad de ver más adelante, Ballagas presenta una historia de amor entre dos personajes construidos de forma completamente disímil del José María reprimido y suicida de El ángel de Sodoma. A partir de este poema, el antillano comenzó la producción de otros en que se encuentran múltiples voces masculinas que expresan casi siempre en primera persona sentimientos eróticos hacia sujetos de su mismo género y algunas de las dificultades relacionadas con atreverse a aceptar una identidad psicológica prohibida por subvertir la heterosexualidad compulsiva en el ámbito público. Esto permite constatar que si bien por una parte el discurso de los científicos no fue el único en circulación, por otra parte había grupos que lo rechazaban

de Sierra Madero y W. Hernández ofrecen discusiones de materiales del siglo XIX, que sirven para complementar el acercamiento al tema. Mira provee un interesante análisis de la recepción de El ángel de Sodoma en España, donde residía Hernández Catá cuando escribió la noveleta (195-202). ${ }^{8}$ La segunda edición de la novelita viene acompañada además de un epílogo del famoso criminólogo español Luis Jiménez de Asúa. El lector interesado debe consultar el libro de Bejel, que provee un útil análisis de ambos textos. Ver también en el estudio de Mira el apartado que éste le dedica a Jiménez de Asúa y a su influencia en el discurso legal en España (178-186). 
asumiendo en cambio propuestas disidentes. ${ }^{9}$ La frase que Virgilio Piñera consigna en el ensayo que he citado anteriormente ("Por fin alguien nos representa") corrobora que la literatura artística estaba comenzando a transfigurar el contradiscurso que los libros de Gide habían ayudado a divulgar.

\section{LA PARATEXTUALIDAD CON FINES DISIDENTES EN ELEGÍA SIN NOMBRE}

Los exponentes del contradiscurso homosexual canalizado a través de la literatura hasta 1950 tuvieron que enfrentar enormes dificultades para hacerlo circular (Lauritsen 35). Esto fue resultado de las restricciones legales que se pusieron a la expresión del tema después de los juicios de 1895 a Oscar Wilde en que los acusadores usaron algunas de sus obras como El retrato de Dorian Gray para mostrar el carácter inmoral del enjuiciado (Hyde 127). La persecución de Wilde implicó una aplicación más férrea de la censura en todas partes (Lauritsen 35). En ocasiones esto significó que aunque una obra ya hubiera sido publicada, su venta podía ser prohibida como ocurrió en Inglaterra en 1928 con la novela The Well of Loneliness de Radcliffe Wall, que se centra en la vida de un personaje femenino homosexual.

En Hispanoamérica es emblemático considerar la campaña contra los escritores asociados con la revista mexicana Contemporáneos (Villaurrutia y Novo) y varios pintores con ellos relacionados, que se inició en Ciudad de México en 1924 con una serie de ataques a expresiones artísticas percibidas como "afeminadas", la forma codificada de apelar la homosexualidad sin sufrir ningún tipo de censura. Algunos de los acusadores solicitaron, en ocasiones al Congreso Nacional, la expulsión de sus puestos de trabajo de sujetos de ese erotismo. Así por ejemplo la asociación conocida como “30-30” planteó que:

Estamos contra el homosexualismo, imitado a la burguesía francesa actual; y entre ellos, favorecidos ahora, y nosotros luchadores incansables, existe el abismo de nuestra honradez que no se vende por un puesto. El gobierno no debe sostener en sus secretarías a los de dudosa condición psicológica. (citado en Monsiváis 213)

La diatriba, redactada en 1934, revela que sus autores aceptaban el discurso médico que proponía que la homosexualidad era una enfermedad, ya que para ellos las personas a quienes denostaban -poetas y pintores homosexuales-sufrían una condición patológica que les debería haber impedido encargarse de empleos en que pudieran no sólo representar

\footnotetext{
${ }^{9}$ Históricamente, el origen de esta reacción contra los médicos se puede trazar en Cuba a una serie de textos que Julián del Casal escribió entre 1888 y 1890. Su intervención comenzó con una crónica periodística en que discrepó con el médico positivista Benjamín de Céspedes, quien había afirmado en el tratado La prostitución en la ciudad de La Habana que los empleados peninsulares de comercio residentes en La Habana eran una fuente de homosexualización y de transmisión de enfermedades venéreas. Después se puede observar en una serie de textos poéticos, también publicados por Julián del Casal en la prensa habanera, en los que creó personajes basados en figuras masculinas que a fines del siglo xix (Ludovico II de Baviera y Petronio) connotaban homoerotismo en el público culto. Para ampliar el tema, consultar a Montero y Esterrich.
} 
públicamente su erotismo, sino servir de modelos en tanto homosexuales exitosos y públicos para la colectividad "marica” mexicana.

A fin de evitar el acoso y la prohibición de sus obras, los escritores opositores del discurso hegemónico que trabajaron en la primera mitad del siglo xx tuvieron que practicar una enorme escrupulosidad en el tratamiento del homoerotismo. Fue por esta razón que desarrollaron un marco expresivo caracterizado por la ambigüedad, la reticencia y la insinuación, es decir, procedimientos retóricos que produjeron un lenguaje cifrado que ocasiona que la(s) primera(s) lectura(s) de esos textos sea(n) casi siempre hermética(s) y se preste(n) a múltiples interpretaciones. En este tipo de escritura, deliberadamente "rara”, también se encuentran abundantes referencias a autores y motivos que denotan homosexualidad, aunque siempre en forma velada, especialmente para los no familiarizados con esa producción cultural. ${ }^{10}$ Este tipo de literatura se vertió casi exclusivamente en la lírica, quizá porque como ha afirmado Jonathan Culler la indeterminación del género “is one of the principal ways of questioning the ordered world which ordinary communicative circuits assume” (168-69). La poesía, que constituye el medio por antonomasia para la expresión literaria de sentimientos y cuya circulación era menor, se convirtió así en el género casi exclusivo en que los escritores homosexuales hispanoamericanos escribieron sobre su erotismo. El testimonio de Piñera sobre la recepción del poema de Ballagas que cité antes comprueba que dicha comunicación era efectiva, específicamente entre los entendidos, de los que él mismo (que era homosexual y culto) es una perfecta ilustración.

La Elegía sin nombre, el primer poema en que Ballagas transfiguró artísticamente su orientación sexual, puede servir de ejemplo para estudiar el tipo de estrategias a que recurrió desde 1936 para encarnarla. Siguiendo la teoría de la paratextualidad propuesta por Gérard Genette, sostengo que desde antes del mismo comienzo del poema, el escritor usó varios elementos para connotar su sexualidad de forma alterna. Según este crítico, la paratextualidad está conformada por un conjunto heteróclito de prácticas y discursos que varían según épocas, géneros, autores y obras. Genette divide el conjunto en dos subgrupos: el peritexto, que incluye el título, los epígrafes y la dedicatoria; y el epitexto, que comprende entrevistas, correspondencias y diarios. Para él: "El paratexto, bajo todas sus formas, es un discurso fundamentalmente heterónimo, auxiliar, es decir, al servicio de otra cosa que constituye su razón de ser, y que es el texto” (16; traducción propia). Con el estudio del peritexto de este poema mostraré que en una época cuando prevalecían la represión y la censura, los escritores homosexuales lo emplearon con propósitos específicos de género y política sexuales. Así propongo que fue gracias al uso peculiar que Ballagas dio a los tres elementos peritextuales de la Elegía que logró no solamente connotar homoerotismo para el lector ideal, sino prepararlo mediante las alusiones a poemas de temas homoeróticos para desentrañar lo que se encuentra desarrollado en extenso y cifradamente en el interior de la composición.

El título, el primer elemento peritextual del poema, sirve desde un punto de vista genológico para apuntar su pertenencia a una forma literaria específica: la elegía. En este caso, el autor optó por un título que hacía referencia a uno de los subgéneros literarios de

\footnotetext{
${ }^{10}$ En los dos primeros capítulos de su Tropics of Desire, José Quiroga analiza correspondencia y poesía de autores latinoamericanos homosexuales del mismo periodo en que escribió Ballagas. Se trata de uno de los mejores estudios actualmente disponibles sobre este tipo de literatura.
} 
más larga tradición en la literatura hispana. Pero a diferencia de autores anteriores y coetáneos, Ballagas no identificó en ninguna parte del impreso a la persona a quien está dedicado. Esta falta de apego por una convención genérica captura de inmediato la atención del lector, ya que al subrayar el escritor dramáticamente la ausencia del nombre del homenajeado, estimula a indagar sobre su identidad y las razones que tuvo para omitirla. Esto quizá haya sido más llamativo para la audiencia local, que ha debido saber que la primera vez que Ballagas compuso una elegía se la dedicó a María Belén Chacón, una humilde cubana cuya muerte era el tema de la obra (Obra 79-80). Como resultado se puede inferir que el homenajeado debía ser un sujeto cuya apelación resultaba socialmente comprometedora, ya que si ésta se hacía podía entenderse como declaración pública de una pasión clandestina entre hombres, algo que estaba proscrito de ser tratado de forma objetiva en la literatura.

Debido a que Ballagas no disfrutaba de libertad de expresión cuando decidió tratar la homosexualidad, tuvo que recurrir a procedimientos retóricos asociados con la censura tales como la reticencia, la insinuación, etc., ya que de otra forma su texto no habría sido publicado; incluso, como parece haber ocurrido, si él mismo pagaba por la edición del cuaderno. Sin embargo, así logró sugerir que había una coincidencia entre lo que su escritura implicaba y la ideología oficial prevaleciente en su época sobre el tema, que obligaba a mantener en silencio las sexualidades no normativas. ¿Por qué, si no por la prohibición que rodeaba la materia, renunciaba a identificar a la persona a la que el texto estaba dedicado? Es posible que si hubiese escrito el nombre del destinatario, algún conocedor hubiese dado el grito de alarma acusándolo de promover un erotismo ilegal y considerado por la mayoría como patológico.

Ballagas, cuya situación financiera no era la de un José Rodríguez Feo, se desempeñaba durante la época de publicación de la elegía como "profesor de literatura española en la Escuela Normal para Maestros de Santa Clara” (Augier 1965: 13) y era consciente de los múltiples peligros -de tipo social, legal y laboral-que lo acechaban si se hubiese atrevido a revelar públicamente una conducta considerada como "anormal”. En este sentido es pertinente recordar que desde sus inicios como literato había sufrido discriminación sexista en numerosas ocasiones. Por ejemplo, cuando su primer libro, Júbilo y fuga, apareció editado en 1931, Enrique Álvarez, del diario habanero El Mundo, escribió una reseña en que presentaba a su autor como afeminado, connotando de esta forma que era homosexual:

Emilio Ballagas en un joven camagüeyano de unos 23 años. Cuerpo diminuto, endeble. Está a punto de doctorarse en Pedagogía. Y como dato característico no ama los deportes. Su hiperestética vida espiritual -en desequilibrio absoluto con su materia- le impide ejercitar el músculo - del cual carece, por otra parte. De una modestia excesiva, pretende siempre recogerse en las espiras de su caracol sonoro para desde ellas darnos su canto furtivo. (citado en Rice 16-17)

La descripción está basada en una serie de elementos que vistos en conjunto connotan emasculación: a pesar de que Ballagas tiene 23 años, su cuerpo es frágil, pequeño y no musculoso; es decir, no era masculino. Además, el polígrafo insinúa que el poeta era un 
hombre desequilibrado porque tenía una intensa vida mental y nunca hacía ejercicios. No muy indirectamente incluso lo llamó pájaro ("para desde ellas darnos su canto furtivo”), vocablo que en el español coloquial cubano era uno de los sinónimos más usados para caracterizar e insultar a un homosexual.

Si el título del poema llama la atención hacia la ausencia del nombre del homenajeado, la lectura consecutiva de los otros elementos paratextuales, los dos epígrafes que aparecen estratégicamente en la primera página del cuaderno, uno de Walt Whitman y otro de Luis Cernuda, permiten deducir que ciertamente se trataba de otro hombre. No es sólo relevante que estos dos autores hayan sido conocidos como homosexuales, sino más importante incluso que las citas que Ballagas escogió provengan de dos libros centrales en la expresión alterna de ese tipo de deseo en ambos. Los epígrafes sirven para enfatizar lo que el título sugería; y este ardid de ofrecer indicios graduales revela la productividad semiótica que el procedimiento podía alcanzar. Además, la referencia a Whitman, similar a la que Gide incluye al comienzo de Corydon cuando describe la sala del apartamento del protagonista, conforma otra pista de filiación entre la obra del discípulo y el maestro (Gide 1924: 2-3).

La primera cita es una transcripción completa, aunque no identificada, del brevísimo poema "Sometimes with One I love" que Walt Whitman escribió en 1867 y que forma parte de "Calamus" en Leaves of Grass:

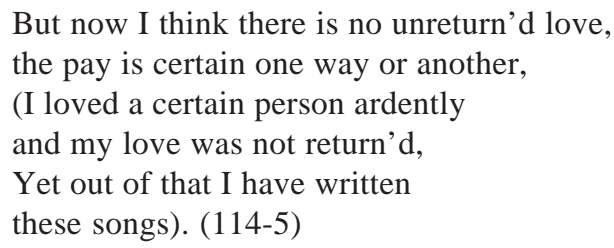

Según el sujeto lírico, a pesar de que el amor no sea correspondido siempre tiene bondades para el sujeto que lo experimenta. Como se verá en la próxima sección, Ballagas adoptó por completo la forma y el contenido del epígrafe: en efecto, aunque no mencionó el nombre del homenajeado, el poema fue escrito como fruto de la relación entre los dos sujetos. De hecho, aquél funciona como una miniatura de lo que el de Ballagas desarrollará en extenso y contiene alusiones a su tema principal -un amor fallido-, lo que se había evitado dar a conocer en el título. Resulta obvio que al incluir la primera inscripción en su lengua originaria, ésta se volvía indescifrable para los lectores que la desconocieran (inicialmente el censor y el editor). Además, al no identificar la proveniencia del epígrafe hacía más difícil localizarlo en el libro del que fue tomado, resguardando de esta forma el contexto homoerótico del que formaba parte. Pero el lector que supiera quién era Walt Whitman y estuviera familiarizado con su obra, podía captar la alusión y atar los cabos (y el testimonio de Piñera que comenté en la primera parte corrobora que numerosas personas lo hicieron). La oración es además importante porque testimonia el conocimiento directo que Ballagas tenía de la obra del norteamericano, quien desde fines del siglo xix había recibido atención de numerosos escritores hispanos, comenzando con su conterráneo José Martí (Molloy 1996). El antillano había estudiado inglés, y del epígrafe es evidente que 
sabía escoger lo que le convenía como lenguaje codificado para la audiencia y fines específicos que tenía en mente.

Por su parte, la segunda cita, proveniente del poema "El joven marino" de Luis Cernuda incluido en Invocaciones, muestra que Ballagas estaba al tanto de la obra revolucionaria del sevillano, que estaba apareciendo en España desde comienzos de la tercera década del siglo xx y quien, como comenté en la primera parte de este trabajo, también recibió una enorme influencia de André Gide. Históricamente, Cernuda es, que se sepa, el primer poeta homosexual peninsular en inscribir explícitamente su orientación erótica en la poesía. ${ }^{11}$ No obstante, como ocurre con el epígrafe de Whitman, la cita no es iluminadora sino para los conocedores muy eruditos, ya que el escritor se aseguró de seleccionar frases que no evidenciaran para un lector lego (haya sido el censor, el editor o el lector indeseado) el contenido homoerótico de las obras (libros o poemas) de donde provienen.

Los versos por los que el antillano optó hacen referencia al lugar en que Cernuda recrea la historia de amor que se narra en la elegía: "Mas ¿qué importan a mi vida las playas del mundo?/ Es ésta solamente quien clava mi memoria” (Ballagas, Elegía 3). La estrofa del poema del español sigue así: "Porque en ella te vi cruzar, sombrío como una negra aurora, / Arrastrando las alas de tu hermosura / Sobre su dilatada curva, semejante a una pomposa rama” (Cernuda, Poesía 192). Ballagas evitó incluir el versículo en donde es explícito que la voz poética se está refiriendo a otro hombre ("Porque en ella te vi cruzar, sombrío como una negra aurora"). Sin embargo, no es difícil conjeturar que lo que más le importaba era que la inscripción contenía una especie de preludio del ambiente en que sitúa la historia sentimental que se cuenta en su propia composición.

En síntesis: es gracias a las connotaciones del título del poema y de las dos inscripciones que se encuentran en la primera página del folleto que la Elegía sin nombre puede interpretarse desde antes de su inicio como texto en que su autor mostró la homosexualidad desde un ángulo contradiscursivo. Al rechazar Ballagas apegarse primero a una convención genérica en la selección del título y luego remitir gracias a los epígrafes a textos pioneros para anunciar el tema homoerótico de la composición, preparó al lector para hacer relaciones más profundas entre los tres escritores y sus textos.

\section{Develando el homoerotismo en la EleGía Sin NOMBre}

Indicio del valor que le concedió, la Elegía sin nombre fue el único poema que Emilio Ballagas publicó en un folleto. Éste contiene dieciseis páginas; el poema propiamente dicho está integrado por ciento veinticuatro versos distribuidos en dieciocho estrofas. Se trata de un hito en la carrera artística del autor, que hasta entonces había escrito composiciones de corta o mediana extensión recogidas en dos volúmenes: Júbilo y fuga (1931) y Cuaderno de poesía negra (1934). Cada uno de estos poemarios refleja un estilo literario diferente. Mientras el primero fue escrito bajo la impronta de la vanguardia liderada en Cuba por Mariano Brull y Eugenio Floritt; en el segundo, en cambio, se nota

\footnotetext{
${ }^{11}$ Aunque breve, el acercamiento a la representación homoerótica en la poesía de Luis Cernuda que hace Mira es recomendable (276-285). Consultar también el estudio de Martin-Clark, uno de los primeros en estudiar el tema en el poeta español.
} 
el impacto de la materia afroantillana que Nicolás Guillén haría memorable (Augier 1972: 9-11). Con la Elegía surgen por primera vez en la producción de este escritor temas asociados con su orientación sexual, que culminarían en la publicación en 1939 de Sabor eterno, el poemario en que la homosexualidad es el tema central, y del que la elegía pasaría a formar parte definitiva. La composición también evidencia otro cambio; por su hermetismo, la lengua en que fue escrita guarda ciertas similitudes con la de Residencia en la tierra de Pablo Neruda y la de dos poetas peninsulares homosexuales: Luis Cernuda y Vicente Aleixandre.

Cuando apareció, la Elegía fue leída como un texto autobiográfico. Por ejemplo, Cintio Vitier afirmó que: "Se trata, por lo pronto, de un poema narrativo, autobiográfico, donde se cuenta una experiencia del amor” (xx). Por su parte, Virgilio Piñera escribió que los eventos allí transfigurados reflejaban una relación amorosa homoerótica que el poeta había tenido: "Por ese entonces Ballagas acaba de salir, como quien dice, de un amor fracasado con una persona de su mismo sexo” (198). No obstante, ninguno de los dos críticos incluyó un análisis textual que mostrara en qué sentido el poema reflejaba la vida sentimental de su autor. Por esta razón se desconoce la identidad del otro hombre, la duración del romance, las razones del rompimiento, etc. Ninguno de los dos comentaristas tampoco consideró necesario precisar los medios que Ballagas usó para representar la relación homoerótica representada en la Elegía. En todo caso, lo que la recepción local sí comprueba es que ya incluso antes de 1936, cuando tenía 28 años, su autor estaba fuera del armario, al menos con amigos y colegas.

La glosa que sigue intenta complementar el análisis precedente de la paratextualidad del poema. Breve por restricciones de espacio, en ella me alejo por completo del tipo de recepción hecha por los dos críticos cubanos. Aclaro: no es que descarte el elemento autobiográfico que dio origen al texto, sino que propongo en cambio una lectura que puede ser verificable a partir de los elementos que allí se encuentran. En vista de que hasta ahora éste no ha sido analizado por separado, en mi comentario combino explicación de su contenido y recursos. Aunque mi acercamiento consiste en una lectura textual ("close reading”), también toma en cuenta algunas de las herramientas críticas disponibles hoy en día para identificar elementos intertextuales e históricos que, como se verá, son claves para descodificar el texto.

Antes que un planto por la muerte de un amante, propongo que la Elegía sin nombre es un lamento por un idilio fracasado. El poema, altamente hermético, se caracteriza por la presencia de recursos que obstaculizan su comprensión para la mayoría de la audiencia y al mismo tiempo exigen la activa participación de los lectores interesados en descifrarlo. Sin embargo, su organización sigue un orden cronológico tradicional que subraya los sentimientos vividos por la voz poética que narra. El idilio se presenta en tres momentos claramente delimitados: la búsqueda, el encuentro y la separación de los amantes. En el primer momento aparece un sujeto -la misma voz narradora- que realiza una excursión vespertina a una playa vecina al lugar en que reside. Ocupa las primeras ocho estrofas; en total, cincuenta y un versos (5-8). El escenario de la historia ("Mar desnudo impaciente mirándose en el cielo”, 5) es la primera de las numerosas alusiones que se encuentran en el interior de la elegía al poema "Al joven marino” de Luis Cernuda. La referencia a este 
escritor, que inició su poema mencionando también el mar (“El mar, y nada más. / Insaciable, insaciable”, 190), es cronológicamente la segunda si se toma en cuenta el epígrafe que comenté en la sección anterior; y está cargada de significado para el lector que conozca el texto aludido en la que una voz lírica lamenta la desaparición de un marino con quien tuvo un romance. La primera, tercera y cuarta estrofas sirven para describir la playa, que aparece como un espacio solitario alejado de un puerto o de alguna otra infraestructura, aunque se implica que está cerca del espacio en que el narrador reside.

En la primera estrofa se encuentran dos de los recursos más visibles usados por Ballagas para connotar la homosexualidad: la insinuación y la falta de puntuación. Para establecer el tono disidente del poema, ambos aparecen traslapados en los versos iniciales: "Mar desnudo impaciente mirándose en el cielo. / El cielo continuándose a sí mismo / persiguiendo su azul sin encontrarlo / nunca definitivo destilado" (5). La insinuación consiste aquí en la humanización de dos elementos naturales visualmente colindantes y con mucho parecido físico; similares incluso en el mismo género gramatical. El escritor presenta el intento de unión del mar con el cielo y el carácter infructuoso de tal acción como anuncios de la relación que se desarrollará en las estrofas posteriores. Por su parte, la falta de puntuación, al mismo tiempo que ocasiona un ritmo más rápido en la lectura de los versos, también hermetiza su sentido. Este procedimiento se vuelve más complejo en el cuerpo del poema; de hecho, la mayor parte de los versos del texto aparece sin puntuación.

El resto de la primera parte del poema (las estrofas segunda, quinta, sexta, séptima y octava) se concentra en caracterizar al narrador. Se trata de un personaje que según sus propias palabras es “demasiado dios trémulo para mis soledades” (5) y a quien "por dentro me iba una tristeza de lejanas / de extraviadas palomas / de perdidas palabras más allá del silencio" (6). Los versos citados implican que en el momento en que la narración comienza, el sujeto lírico no estaba involucrado sentimentalmente con otra persona y resentía la soledad. Aunque el paseo por la playa podría entenderse como el medio al que el sujeto recurría para distraerse de su soledad, al mismo tiempo podría interpretarse como una referencia a su participación en la sociabilidad homosexual de la época. Varios estudios recientes han revelado que durante las primeras décadas del siglo xx existían subculturas homosexuales en Latinoamérica. Según sus autores, una de las actividades más prevalecientes en ellas era precisamente el ligue informal que se llevaba a cabo en espacios públicos (Salessi 309; Green 23). En el caso de un país isleño como Cuba es perfectamente lógico pensar que las playas aledañas a pueblos y ciudades hayan sido reductos privilegiados en el tiempo propicio para la expresión del deseo homoerótico. Como el lector recordará, el narrador de la elegía se dirige en horas vespertinas a una playa solitaria donde conocerá a otro hombre.

El segundo momento de la elegía, en que se recrea el encuentro de los dos personajes, es el más breve (8-10): ocupa solamente cuatro estrofas (veintisiete versos). La novena estrofa inaugura esta sección presentando juntos al narrador y a su compañero. Pero a diferencia de lo que hizo con la voz lírica, Ballagas describe al nuevo personaje de forma ambigua. La primera vez que lo hace, éste está acostado en la arena; el poeta escribió: “aunque tu cuerpo bello reposara tendido / tú avanzabas amor te empujaba el destino” (8). A pesar de que éste es un instante clave tanto en el desarrollo del poema como para su interpretación, ya que es la secuencia en que los dos sujetos se conocen, no hay ninguna 
marca lingüística que permita determinar con certeza el género sexual del nuevo personaje. No obstante, en estos dos versos el sustantivo “cuerpo" y los adjetivos "bello"y "tendido" de género masculino permiten que el lector pueda inferir que se trata de un hombre.

En la medida en que los dos sujetos comienzan a caminar y charlar, el narrador describe a su nuevo compañero mediante metáforas; de hecho, las undécima y duodécima estrofas comparten esta similitud estilística (9-10). Para insinuar que el hombre era joven el narrador dice: “y era la primavera inquieta de tu sangre”; para sugerir que era alto, "mástil columna torre en ritmo de estatura"; y para precisar su pertenencia étnica, "una música presa en tus quemadas carnes”. En esta ocasión, Ballagas recurrió a recursos típicos de la poesía para sugerir sin tener que precisar el género sexual del otro sujeto. Al mismo tiempo también usó el apóstrofe para evitar así usar las marcas de género gramatical. El empleo de esta figura literaria constituye otra referencia intertextual a "Un joven marino" de Cernuda en que este recurso aparece de manera recurrente.

Además, en la estrofa también se puede notar que el escritor tuvo en cuenta la futura recepción del texto para comunicar mensajes claves. En efecto, parece haber asumido que el lector ideal captaría que la representación del encuentro no seguía las costumbres generales de la época y del país en que se escribió el texto y en que un paseo como el descrito habría sido interpretado como sospechoso por un lector heterosexual y como un ligue por un lector homosexual. En el contexto caribeño que condicionaba la lectura del poema en la primera mitad del siglo xx era infrecuente -y aún hoy lo sigue siendo- que un hombre heterosexual caminara por la playa en el atardecer o la noche con una desconocida, y mucho menos que una mujer sola paseara por una playa a esa misma hora. Eso era algo en cambio que quizá podía realizar -muy arriesgadamente- una pareja heterosexual establecida (que no es lo representado en el poema) y con toda certeza dos hombres homosexuales interesados en tener una relación sexual casual en una playa (que es en realidad lo que allí se recrea).

La tercera parte de la elegía, que comprende las ocho estrofas finales con un total de sesenta y cuatro versos (10-15), trata de la separación de los amantes, evento que ocurre en el mismo ambiente marino al anochecer del día narrado en las dos secciones anteriores. De forma significativa hay un paralelo entre el deslinde de la segunda y la tercera partes de la elegía y la separación de los dos personajes, que se establece a partir del recuento que hace el narrador de una acción que ejecuta su compañero. De hecho, la última sección del poema, que comienza en la decimotercera estrofa, se inicia presentando al amante separado del sujeto lírico: "Nadabas / yo quería amarte con un pecho / parecido al del agua que atravesaras ágil” (10). Aquí aparece otra referencia intertextual al poema "Al joven marino” de Luis Cernuda. En los versos que acabo de citar se encuentran ecos de éstos de Cernuda:

El mar, única criatura

Que pudiera asumir tu vida poseyéndote.

Tuyo sólo en los ojos no te bastaba,

$\mathrm{Ni}$ en el ligero abrazo del nadador indiferente. (190) 
Poco después se insinúa que el amante falleció, posiblemente ahogado: "te trajeron las olas" (10), verso que también alude a otro de "El joven marino": "Flotó tu cuerpo, apenas deformado por las nupciales caricias del mar” (195).

No obstante, a diferencia de las dos primeras partes de la elegía en que el tiempo verbal que predomina es el imperfecto, el narrador emplea reiteradamente el presente ("Sé que vives y alientas / con un alma distinta cada vez que respiras”) a partir de la decimocuarta estrofa, afirmando así que el otro hombre está vivo (11). Estos versos sirven para aclarar el desenlance del romance y apuntan a revelar que lo representado es un rompimiento, no una separación por la muerte de uno de los amantes como se habría podido pensar si se le prestaba solamente atención al título. Por cierto, ésta sería la verdadera razón de la ausencia de la identificación del destinatario del poema si seguimos la lectura de Vitier y Piñera; como los hombres se separaron, entonces el poeta no podía dedicarle la composición a su ex amante. Desde la estrofa mencionada hasta el final, el narrador describe minuciosamente el dolor que experimenta. Como en el epígrafe de Whitman, aquí la voz lírica percibe el acto de escribir como el medio más eficaz de recordar y rendirle homenaje a su compañero: "Yo te doy a la vida entera del poema" (12). Este empleo adicional de la intertextualidad reafirma las similitudes de las experiencias descritas por los dos escritores.

Cerca del final la voz lírica afirma que se mudará del poblado en que es residente ("me iré mañana me perderé bogando / en un barco de sombras”, 12) porque no puede soportar el dolor asociado con la ausencia del compañero. La elegía concluye con otro ejemplo de intertextualidad, esta vez a los versos fínales de “A un joven marino”. Cernuda había terminado su poema de esta forma: "Así tu muerte despierta en mí el deseo de la muerte, / Como tu vida despertaba en mí el deseo de la vida” (196). Ballagas, por su parte, concluye el suyo así: "Los pechos de la muerte me alimentan la vida" (15).

De la glosa puede apreciarse que Elegía sin nombre cuenta y canta las experiencias que un sujeto homosexual narra después de terminar un romance con otro hombre. A diferencia de los escritores que estaban propagando el discurso impuesto por los médicos (como se vio a propósito de El ángel de Sodoma de Alfonso Hernández Catá), Ballagas creó en este poema una representación desprejuiciada de homoerotismo. Tal como algunos de sus primeros lectores percibieron, se trata de "un canto de guerra" o "una pieza de convicción”, es decir, el primer texto público de un escritor que comenzaba a discrepar con el discurso sexual prevaleciente en Cuba. La disidencia de Ballagas se observa en el ángulo desde el cual situó el texto. Mientras que en las otras obras sobre homosexualidad, literarias o no literarias, tanto finiseculares como coetáneas, ésta se mostraba como una patología, Ballagas la recrea de manera muy similar a la sexualidad normativa. No en balde la elegía está construida como una variación de un poema romántico en que un amante lamenta un amor fallido. ¿Hay algo literariamente más común que eso?

Reveladoramente en la composición se presentan dos sujetos que establecen la relación sentimental en una playa y en un atardecer, elementos que metaforizan la discriminación que sufrían los homosexuales locales, quienes debían esconder su erotismo y reprimirse de expresarlo en público porque de lo contrario habrían sido legalmente perseguidos. Aquí es pertinente recordar la frase que según Virgilio Piñera varios lectores expresaron después de leer el poema: “Por fin alguien nos representa”. Es posible que éstos 
la hayan usado para caracterizar su rechazo de las imágenes que la literatura mayoritaria estaba propagando sobre ellos; aquéllas, altamente prejuciadas, fallaban en mostrar la humanidad y normalidad de los homosexuales y, como por ejemplo ocurre en El ángel de Sodoma, estimulaban a los homosexuales a rechazar su erotismo e incluso proponían el suicidio como medio de evitar el deshonor de asumir una sexualidad “aberrante”. La elegía en cambio subrayaba no sólo que el sujeto homosexual amaba y sufría como cualquier otro ser humano, sino que era parte reprimida y por esa razón invisible de la nación. El texto de Emilio Ballagas constituye, en última instancia, una ilustración de lo que en su Historia de la sexualidad Michel Foucault denominó el “discurso de rechazo”, es decir, aquél en que "la homosexualidad se puso a hablar de sí misma, a reivindicar su legitimidad o su naturalidad” (124).

\section{Conclusión}

Entre 1920 y 1950, un grupo de poetas homosexuales hispanoamericanos comenzó a crear representaciones literarias novedosas de su sexualidad. La producción y circulación de estos textos en Ciudad de México, Buenos Aires y La Habana implicó el surgimiento de otro tipo de tratamiento del homoerotismo en una literatura que desde fines del siglo XIX (Martí) hasta 1920 (Darío, González) se había caracterizado por la divulgación de imágenes que reproducían el discurso médico, el cual conceptuaba las relaciones afectivas y eróticas entre personas del mismo sexo como patológicas. La ideología prohomosexual que André Gide contribuyó a hacer circular con Corydon en la década del veinte fue decisiva en el desarrollo de la nueva tradición que ejemplifican poetas como Xavier Villaurrutia, Juan Rodolfo Wilcock y Emilio Ballagas.

La escritura homoerótica disidente se caracterizó por la inclusión abundante de personajes que al asumir una identidad prohibida confrontaban numerosas dificultades asociadas con la práctica de un erotismo no normativo; estas voces coinciden en expresarse, aunque no por accidente, en un lenguaje reticente y en ocasiones hermético. Como probé, este estilo fue estratégico, ya que constituyó un tipo de insubordinación puesta en práctica por sujetos que, debido a que no tuvieron libertad de expresión para criticar abiertamente el discurso impuesto por los médicos, se vieron en la necesidad de desarrollar una escritura polivalente con la que al mismo tiempo que pasaron las exigencias de la censura, pudieron incluir, no obstante, representaciones desprejuiciadas de homoerotismo.

El estudio sistemático de los escritores homosexuales de la primera mitad del siglo xx usando perspectivas de análisis informadas por los estudios de género y sexualidad es una tarea que apenas está comenzando. Con este ensayo, en el que además usé la teoría de la paratextualidad, he intentado llamar la atención por una parte hacia el tipo de retórica prevaleciente en esa escritura y por la otra ofrecer un ejemplo del tipo de lectura que esa familia de textos requiere. Cuando sepamos más de poetas como Villaurrutia y Wilcock, también tendremos un panorama más completo de las maneras en que los homosexuales hispanoamericanos de la primera mitad del siglo xx respondieron al discurso del poder, que los condenaba y que sus colegas heterosexuales adoptaron. Como he mostrado a propósito de Ballagas, aunque el sujeto homosexual fue reprimido, éste no sólo no se dejó 
dominar por la conceptualización impuesta por los médicos sino que desarrolló estrategias para rechazar esa seudoformulación científica y hacer así circular un discurso alternativo que mostraba que los homosexuales eran tan normales como la mayoría.

\section{BiBLIOGRAFÍA}

Acero, Rosa María. Novo ante Novo. Madrid: Editorial Pliegos, 2003.

Aleixandre, Vicente. Mis mejores poemas. Madrid: Editorial Gredos, 1956.

Augier, Ángel. "Prólogo". Compilación de poesía seleccionada y anotada. Emilio Ballagas. La Habana: Instituto Cubano del Libro, 1972. 7-18.

"Prólogo". Órbita de Emilio Ballagas. Emilio Ballagas. La Habana: Ediciones Unión, 1965. 7-18.

Balderston, Daniel. "Poetry, Revolution, Homophobia: Polemics from the Mexican Revolution”. Hispanisms and Homosexualities. Sylvia Molloy y Robert M. Irwin, eds. Durham: Duke UP, 1998. 57-75.

Ballagas, Emilio. Elegía sin nombre. Poema de Emilio Ballagas. La Habana: Imp. Ucar, García y Cía., 1936.

Sabor eterno; poemas. La Habana: Editorial Héroe, 1939.

"Cuaderno de poesía negra”. Obra poética. La Habana: Editorial Letras Cubanas, 1984. 77-97. “Júbilo y fuga”. Obra poética. La Habana: Editorial Letras Cubanas, 1984. 50-74.

Barba Jacob, Porfirio. Rosas negras (antología poética). Luis A. de Villena, ed. Valencia: Mestral, 1988.

Barredas, Pedro M. "Patriarcado, poeta, poesía: la lírica de Emilio Ballagas”. Revista Iberoamericana LVI/152-153 (1990): 1153-70.

Bejel, Emilio. Gay Cuban Nation. Chicago: U of Chicago P, 2003.

Casal, Julián del. Poesías completas y pequeños poemas en prosa. Miami: Ediciones Universal, 1983.

Cernuda, Luis. Prosa completa. Barcelona: Barral Editores, 1975. Poesía completa. Barcelona: Barral Editores, 1974.

Céspedes, Benjamín de. La prostitución en la ciudad de La Habana. La Habana: Establecimiento Tipográfico O’Reilly, 1888.

Culler, Jonathan. Structuralist Poetics. Structuralism, Linguistics, and the Study of Literature. Ithaca: Cornell UP, 1975.

Darío, Rubén. "Purificaciones de la piedad". Obras completas III. Madrid: Afrodisio Aguado, 1950. 468-74.

Esterrich, Carmelo. “Casal, Julián del”. Latin American Writers on Gay and Lesbian Themes. David W. Foster, ed. Westport, CT: Greenwood Press, 1994. 105-8.

Foucault, Michel. Historia de la sexualidad. La voluntad de saber. Ulises Guiñazú, trad. México: Siglo XXI Editores, 1977.

Fowler, Víctor. La maldición. La Habana: Editorial Letras Cubanas, 1998.

Genette, Gerard. Seuils. París: Éditions du Seuil, 1987.

Gide, André. Si la semilla muere. Madrid: Losada, 2003. Corydon. Madrid: Odisea, 2002. 
If it Die: An Autobiography. Dorothy Bussy, trad. Nueva York: Random House, 1935.

Si le grain ne meurt. París: Librairie Gallimard, 1924.

Corydon. París: Librairie Gallimard, 1924.

Si le grain ne meurt:souvenirs d'enfance et de jeunesse. París: Ernest Flammarion, 1920.

González Castillo, José. Los invertidos. Buenos Aires: Sociedad General de Autores de la Argentina, 1957.

Green, James N. Beyond Carnival: Male Homosexuality in Twentieth-Century Brazil. Chicago: U of Chicago P, 1999.

Hernández, Wilfredo. "Medicina, homosexualidad y política en Cuba finisecular: la polémica de los dependientes españoles de comercio”. Revista de Estudios Hispánicos 40 (2006): 25-48.

Hernández Catá, Alfonso. El ángel de Sodoma. Valparaíso: El Callao, 1929.

Hyde, H. Montgomery. The Trials of Oscar Wilde. Birmingham: Leslie B. Adams, 1989.

Irwin, Robert. “As Invisible as He Is: The Queer Enigma of Xavier Villaurrutia”. Reading and Writing the Ambiente. Queer Sexualities in Latino, Latin American, and Spanish Culture. Susana Chávez-Silverman y Librada Hernández, eds. Madison: U of Wisconsin P, 2000. 114-46.

Lauritsen, John y David Thorstad. The Early Homosexual Rights Movement (1864-1935). Nueva York: Times Change Press, 1974.

Martí, José. “Oscar Wilde”. Obras escogidas. Madrid: Aguilar, 1953. 476-80.

Martin-Clark, Philip. Art, Gender, and Sexuality: New Readings of Cernuda's Later Poetry. Leeds: Maney Pub. for the Modern Humanities Reseach Association, 2000.

Mira, Alberto. De Sodoma a Chueca. Una historia cultural de la homosexualidad en España en el siglo XX. Barcelona: Editorial EGALES, 2004.

Molloy, Sylvia. "His America, Our America: José Martí Reads Whitman”. Modern Language Quarterly 57/2 (1996): 369-79.

"Too Wilde for Comfort: Desire and ideology in Fin-de-Siècle Spanish America". Social Text 10/2-3 (1992): 187-201.

Monsiváis, Carlos. "El mundo soslayado (donde se mezclan la confesión y la proclama)". La estatua de sal. Salvador Novo. Ciudad de México: Consejo Nacional de la Cultura, 1998.

Montenegro, Carlos. Hombres sin mujer. Ciudad de México: Editorial Masas, 1938.

Montero, Oscar. Erotismo y representación en Julián del Casal. Atlanta: Rodopi, 1993.

Neruda, Pablo. Residencia en la tierra. Madrid: Ediciones del Árbol, 1935.

Novo, Salvador. Nuevo amor y otras poesías. México: Fondo de Cultura Económica, 1984.

Oropesa, Salvador. The Contemporáneos Group: Rewriting Mexico in the Thirties and Forties. Austin: U of Texas P, 2003.

Paz, Octavio. Cuadrivio. México: Joaquín Mortiz, 1965.

Piñera, Virgilio. "Ballagas en persona”. Poesía y crítica. La Habana: Consejo Nacional para la Cultura y las Artes, 1994. 192-209. 
“Permanencia de Ballagas”. Poesía y crítica. La Habana: Consejo Nacional para la Cultura y las Artes, 1994. 225-29.

Pollard, Patrick. André Gide: Homosexual Moralist. New Haven: Yale UP, 1991.

Quiroga, José. Tropics of Desire. Interventions from Queer Latino America. Nueva York: New York UP, 2000.

Rice, Argyll Pryor. Emilio Ballagas. Poeta o poesía. México: Ediciones Andrea, 1966. Rodríguez Acosta, Ofelia. En la noche del mundo. La Habana: La Verónica, 1940. La vida manda. Madrid: Biblioteca Rubén Darío, 1929.

Rodríguez Núñez, Víctor. "El cielo del rehén: la insubordinación sexual en los versos tardíos de Emilio Ballagas”. Revista de Crítica Literaria Latinoamericana 55 (2002): 133-56.

Salessi, Jorge. Médicos, maleantes y maricas. Rosario: Beatriz Viterbo Editora, 1995.

Sheridan,Guillermo. Los contemporáneos ayer. México: Fondo de Cultura Económica, 1983.

Sierra Madero, Abel. La nación sexuada: relaciones de género y sexo en Cuba (18301855). La Habana: Editorial de Ciencias Sociales, 2002.

"La policía del sexo. La homofobia durante el siglo XIX en Cuba”. Ensayo inédito.

Valle, Carmen. "El discurso poético de Porfirio Barba Jacob: marginalidad y evolución estética”. City University of New York. Tesis doctoral. 1992.

Vallejo, Fernando. Barba Jacob. El mensajero. Bogotá: Planeta, 1997.

Villena, Luis Antonio de. "Introducción invitatoria y esencial a Porfirio Barba Jacob”. Rosas negras (antología poética). Porfirio Barba Jacob. Valencia: Mestral, 1988. 727.

Villaurrutia, Xavier. Nostalgia de la muerte. Buenos Aires: Sur, 1938.

Vitier, Cintio. "La poesía de Emilio Ballagas”. Emilio Ballagas: Obra poética. Edición póstuma. Miami: Mnemosyne, 1969. v-xli.

Wilcock, Juan Rodolfo. Paseo sentimental. Buenos Aires: Editorial Sudamericana, 1946. Whitman, Walt. Leaves of Grass and Other Writings. Nueva York: W.W.Norton, 2002. 